Lehtovaara, J., Mustonen, I., Peuronen, P., Seppänen, O., and Peltokorpi, A. (2019). "Implementing takt planning and takt control into residential construction" In: Proc. $27^{\text {th }}$ Annual Conference of the International. Group for Lean Construction (IGLC), Pasquire C. and Hamzeh F.R. (ed.), Dublin, Ireland, pp. 417-428. DOI: https://doi.org/10.24928/2019/0118. Available at: 〈www.iglc.net>.

\title{
IMPLEMENTING TAKT PLANNING AND TAKT CONTROL INTO RESIDENTIAL CONSTRUCTION
}

\author{
Joonas Lehtovaara', Iina Mustonen², Petteri Peuronen ${ }^{3}$, Olli Seppänen ${ }^{4}$, and Antti \\ Peltokorpi $^{5}$
}

\begin{abstract}
This study addresses the suitability of takt planning and takt control (TPTC) for the interior phase in residential construction projects. The purpose is to gain understanding on how to best implement TPTC in residential construction.

The study was conducted as a qualitative case study, by investigating TPTC implementation for the interior phase in a residential construction project in Finland. The initial motivation for takt implementation was to achieve better flow efficiency and radically shortened production duration. The analysis was based on 14 interviews, site observation, data from digital control tools and workshops, and aimed to identify lessons learned as well as required future development actions in TPTC implementation.

The findings indicate that TPTC is well suitable for the interior phase and even in the first pilot project it substantially reduced the project duration. However, certain barriers, as well as enablers, were identified in both planning and control phases, which can be adopted as a basis for continuous development. For example, more detailed planning of wagons and tighter collaboration between all the project participants should be considered. The study represents the category of applied research and has implications for achieving the full potential of takt planning and control in the future.
\end{abstract}

\section{KEYWORDS}

Takt planning, takt control, lean construction, residential construction

1 Doctoral Candidate, Department of Civil Engineering, Aalto University, Finland, joonas.lehtovaara@aalto.fi

2 Site Engineer, Fira Oy, Finland, iina.mustonen@fira.fi

3 Production Engineer, Fira Oy, Finland, petteri.peuronen@fira.fi

4 Professor of Practice, Department of Civil Engineering, Aalto University, Finland, Olli.seppanen@aalto.fi

5 Assistant Professor, Department of Civil Engineering, Aalto University, Finland, antti.peltokorpi@aalto.fi 


\section{INTRODUCTION}

Production planning and control are key contributors to successful and flow-efficient construction projects (e.g., Koskela 1992). During the last two decades, the Lean Construction community has invested considerable effort to develop tools and systems for more efficient production planning and control, and several case studies have been reported where lean methods were employed to successfully improve the construction workflow. Especially the implementation of collaborative planning methods such as Last Planner System (LPS, Ballard 2000) and the shift from activity-based to location-based management (LBMS, Kenley \& Seppänen 2010) have shown their potential in improving flow efficiency. Recently, production planning and control methods Takt Time Planning (TTP) and Takt Planning and Control (TPTC) have received attention within the Lean Construction community. TTP and TPTC have shown great potential in radically decreasing production durations, and for example, Frandson et al. (2013) and Binninger et al. (2018) have documented 55\% and $70 \%$ reductions, respectively, in durations by implementing takt production.

Takt is a lean concept, which refers to a constant production time in different work tasks. According to by Hopp \& Spearman (2008), "takt time is the unit of time within which a product must be produced in order to match the rate at which that product is needed". In construction, takt practically means balancing the work tasks in order for them to proceed in the same beat, around the same unit of time. Takt in construction has been explored especially in California by Frandson \& Tommelein (e.g. 2016, defined as TTP, takt time production), and in Germany, by Dlouhy \& Binninger (e.g. 2016, defined as TPTC, takt planning and takt control). Although there are differences between the approaches, the basic principle of working around the balanced beat exists in both systems. Takt planning is based on identifying repetitive processes and sub-processes, after which production is optimized from the process perspective, and not from the product perspective which leads to sub-optimization (Dlouhy et al. 2016). Thus, the benefit of takt surfaces from its structured and methodological way of planning as well as daily control of the production, and therefore, achieving stability and continuous flow (Tommelein 2017). For clarity, we refer to both approaches as takt planning and takt control, TPTC.

As takt planning and control is by its nature suitable for highly repetitive work (Binninger et al. 2018), it would appear to be suited especially well for the interior phase of residential construction. However, little empirical research exists on TPTC implementation in residential construction projects. Also, only a few studies have documented the actual implementation and critical analysis of takt controlled cases (listed in Table 1). Documented cases cover mainly factory and hospital projects, while only Vatne \& Drevland (2016) have observed the implementation and carried out critical analysis of takt planning in residential projects.

Therefore, it is necessary to examine ways in which TPTC could improve the flow efficiency and reduce production duration in residential construction. In addition, research is needed on investigating that are the methods used in other cases applicable to repetitive residential construction. The study aims to contribute to the mentioned research gaps by answering the following questions: 1) Is takt planning and control suitable for improving 
flow efficiency and shortening overall duration in the interior phase of a residential construction project? and 2) which barriers, enablers and possible actions for development appear while implementing takt planning and control in residential construction?

Table 1: Documented takt cases that include a detailed analysis of the implementation

\begin{tabular}{ll}
\hline \multicolumn{1}{c}{ Authors, year } & \multicolumn{1}{c}{ Case and primary observations } \\
\hline Binninger et al. 2018 & $\begin{array}{l}\text { Retail space renovation: Reduced production duration by 70\%; } \\
\text { extended planning and tight integration of participants required } \\
\text { Etges et al. 2018 }\end{array}$ \\
Dlouhy et al. 2016 & $\begin{array}{l}\text { Sesistance to change } \\
\text { Large scale vehicle factory: Increased transparency, reduced } \\
\text { production duration by 45\% } \\
\text { Infrastructure project: Reduced waste (overproduction and } \\
\text { wait), enhanced buffer control }\end{array}$ \\
Frandson \& Tommelein, & $\begin{array}{l}\text { Hospital, interior phase: } \text { Takt planning shortened duration; } \\
\text { require a more holistic approach to planning and strategic usage } \\
\text { of buffers }\end{array}$ \\
Frandson et al. 2013 & $\begin{array}{l}\text { Hospital, exterior phase: Reduced production duration by 55\%; } \\
\text { obstacles regarding communication, commitment, and support } \\
\text { High-rise building with apartments and kindergarten: } \\
\text { Reduced waste and duration, increased transparency but also } \\
\text { obstacles including the tradition of working and revenue models }\end{array}$ \\
\hline
\end{tabular}

\section{RESEARCH METHOD}

The research was conducted as a qualitative case study, focused on the interior phase of a construction project located in Helsinki, Finland. The data were primarily collected through semi-structured theme interviews, and in total, 14 interviews of the GC and trade partners' employees were conducted. Interviewees consisted of site managers, GC project personnel (such as procurement and design managers), as well as heads and workers of trades. Interview themes included technical details of planning, control, management, training and visualization, but also addressed social aspects, such of the involvement of stakeholders in the planning process, training of methods and tools, leadership, and overall satisfaction of implemented lean principles, processes and tools. Two of the interviews were conducted as group interviews, where the issues were analyzed with GC's site personnel. To triangulate the data collection and increase the reliability of the study (Patton 1999), data collection also included site visits, observation of project documentation as well as participation in production meetings. The observation addressed themes similar to those in the interviews. Site visits and meeting observations were conducted thorough the interior phase approximately once per week.

In addition to interviews and observation, some useful insights were also observed through digital monitoring tools which were piloted in the project by the GC (tools are introduced more thoroughly in case description). The implementation was done to gain 
quantitative data for further analysis of the production. However, as the interviews indicated that the quantitative data suffered from irregular tracking and poor utilization rate of tools, instead of conducting a thorough data analysis the tracking results were only used to support the qualitative observations.

The data were clustered according to the representative work stages, which were further analyzed through the 5-why root cause analysis. The 5-why analysis was chosen for its simplicity and efficiency and because it is exceptionally well suited to analyzing the production (Jabrouni et al. 2011). The analysis was conducted in order to understand the process on a deeper level and to connect the visible observations with root causes, which generally remain undiscovered during production. At the same time, recommendations for further process development were presented.

Furthermore, the observations and identified recommendations were synthesized by dividing them into two categories: planning (actions that need to be addressed before the production) and control (addressed during the production). The synthesis was conducted to provide a systematic way to learn and implement the actions in the future. Finally, conclusions were drawn regarding the actions that were seen to be the most critical for effective takt planning and takt control. The study was limited to the interior phase, and more specifically, to the work stages inside the apartments.

\section{RESULTS AND ANALYSIS}

\section{CASE DESCRIPTION AND TAKT PLANNING}

The studied case project is a seven-story residential building project located in Helsinki, Finland. The project was conducted through design-build delivery, orchestrated by the general contractor Fira, which was responsible for TPTC implementation. The building consists of 42 apartments, and their floor design varies from $31 \mathrm{~m} 2$ studio apartments to $83 \mathrm{~m} 2$ three-bedroom apartments. Also, floor designs vary in their shape and therefore are relatively challenging regarding repetitive planning. The production phase was preliminarily scheduled for 15 months, which provided a starting point for the takt planning.

The goal of the takt implementation pilot was to radically decrease the duration of the interior phase, without increasing costs or decreasing quality. The planning phase partially adapted the steps presented by Frandson et al. (2013): (1) Gather information, (2) Define areas of work (zones), (3) Understand the trade sequence, (4) Understand the individual trade durations, (5) Balance the workflow and (6) Establish the production plan. The planning phase consisted of two iterations. The first iteration was based on theoretical durations of the tasks combined with the main contractor's data and experience, whereas in the second iteration subcontractors were engaged through interviews and workshops. The main contractor attempted to include all the subcontractors in the planning, even though the decision to implement takt planning in the interior phase was done after most of the subcontractors were already contracted by the project.

A single apartment was determined as a takt area and was divided into two SSU's (standard space units): the bathroom and the rest of the apartment. The takt time was set as one day, which was justified to be reasonable for the given small, easy-to-visualize, repeatable takt areas and suitable for the goal of radically reducing production duration 
(Binninger et al. 2018). As an exception to one-day takt, wall levelling and painting were planned using a takt time of one week. Daily planning of the mentioned tasks would have required more thorough planning with the subcontractor and was set for improvement action for following projects. Some of the tasks were also divided for two days (batch size 0.5 ) and some contained multiple locations in same day (batch size $>1$ ). The initial takt plan focused on the apartments, and the takt plan for the other functional areas such as storage and shared spaces were determined separately, which also functioned as backlog areas. After the second iteration, the production time for the interior phase was scheduled for 18 weeks. The estimated time saving through takt planning was ten weeks, a saving of approximately one third (35\%) compared to the situation where the detailed planning would be done with traditional methods.

The schedule after the second iteration is presented in Figures 1 and 2. Figure 1 represents train 1, which includes apartment dry areas. Figure 2 represents train 2, which includes apartment bathrooms. In the study the interior phase is inspected through three stages, which are reflected in the different issues that were observed during the process, and which provide a tangible overview of the interior phase. Early-stage production and ramp-up includes painting and tasks before the painting, and include roughly the first six weeks of the 18-week phase. Mid-stage production considers tasks from ceiling equipment to floor laminate installation, spanning roughly six weeks. Last, end-stage production and handover roughly consists of the last six weeks of the interior phase.

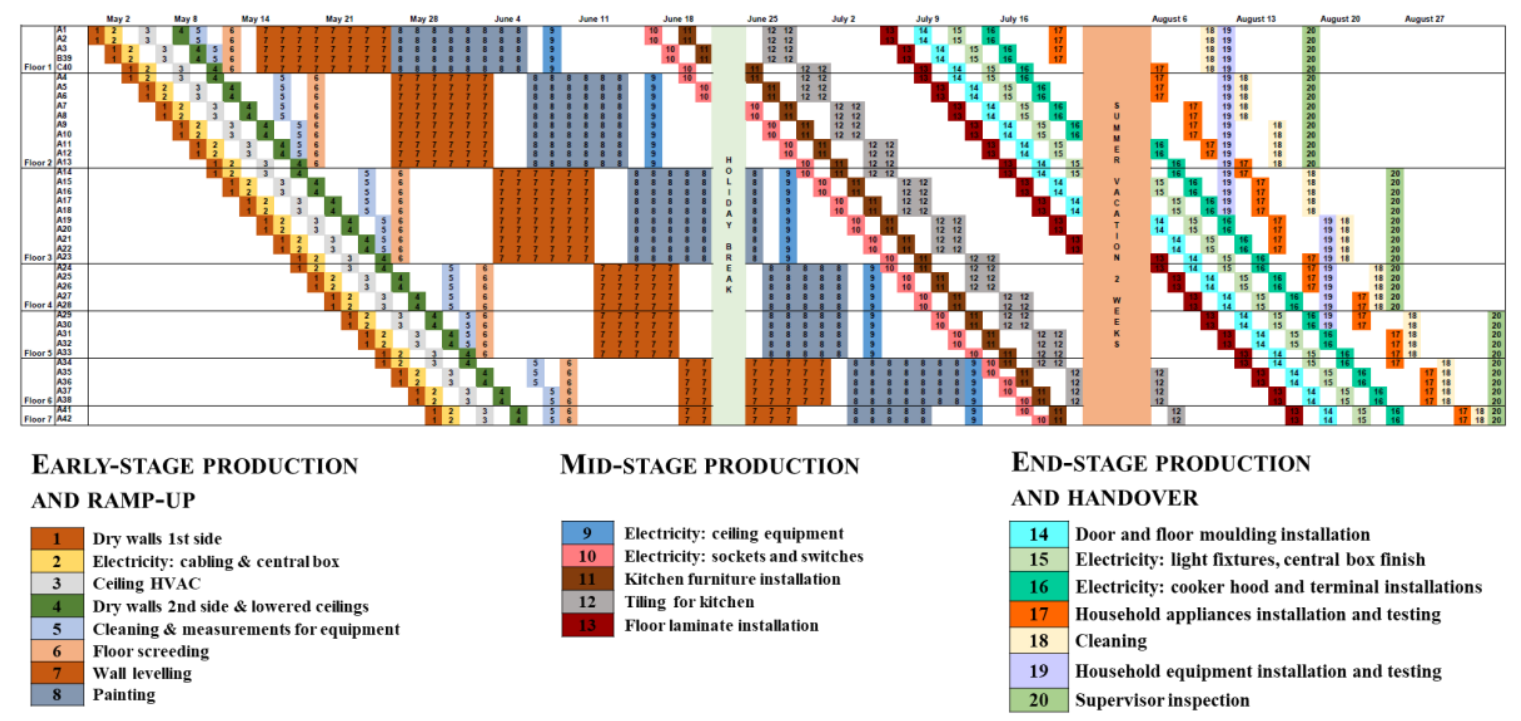

Figure 1 Takt schedule for the interior phase (train 1, dry areas in apartments) 


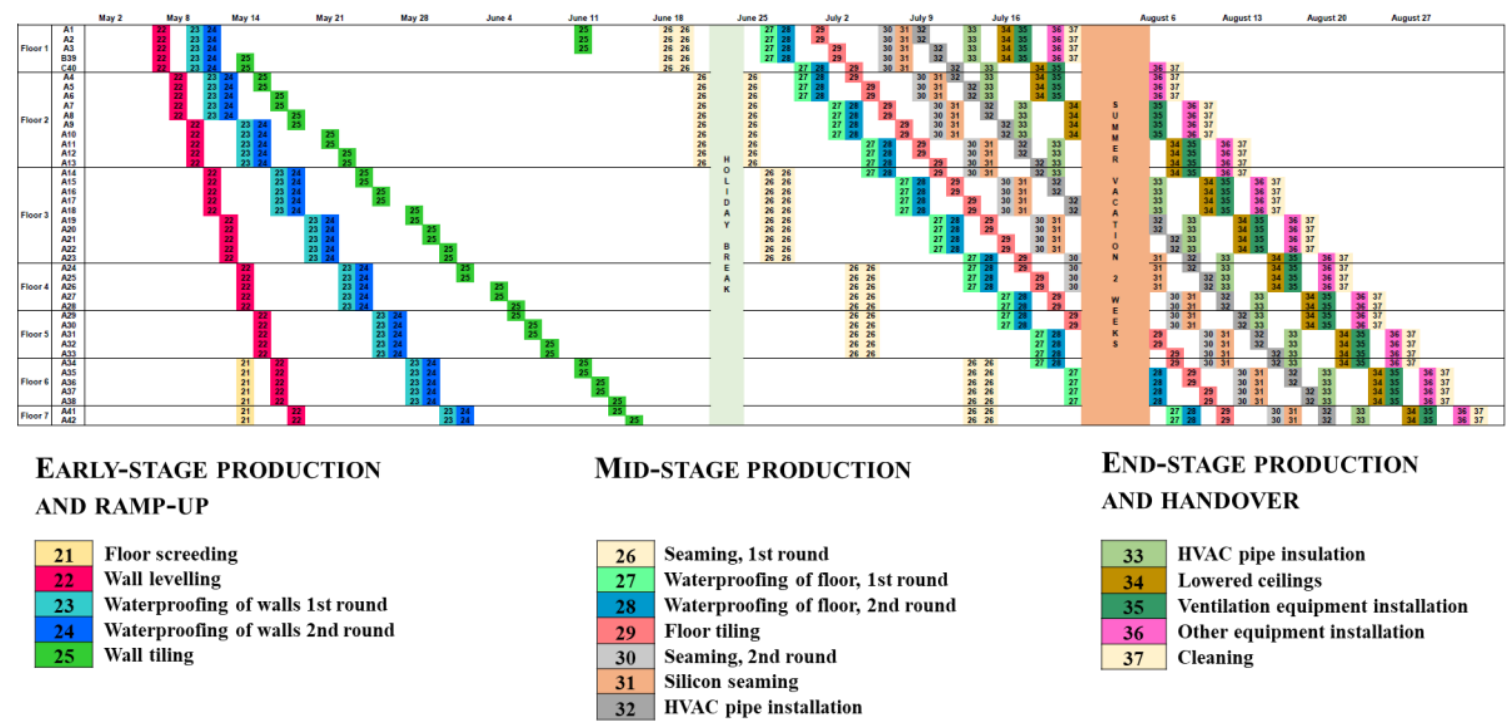

Figure 2 Takt schedule for the interior phase (train 2, bathrooms)

Plenty of effort was put in addressing the flow between the trains. Some of the tasks were possible to complete simultaneously in both locations, but some tasks, such as floor screeding, wall levelling and painting (tasks 6-8) required the usage of both spaces, which blocked the movement of the second train. This resulted in a three-week idle in bathroom train in May-June. Flow between the trains was found to be a problem also later in the control phase, where the avoidance of train clashes required significant amount of management effort.

The production was controlled through three weekly site meetings: 1) the takt control meeting which covered issues related to schedule; 2) the contractor meeting which covered issues related to technical issues; and 3) the site manager meeting which covered general contractor's internal issues. In addition to piloting TPTC, the main contractor also implemented several new digital project management and control tools for the interior phase. The most remarkable implementation was a new digital schedule planning and control tool SiteDrive, which allowed real-time inspection and control of the schedule through a mobile application. In addition, the production was tracked with the quality inspection tool Congrid and with indoor sensors which tracked drying, indoor conditions, and temperature in real time.

\section{EARLY-STAGE PRODUCTION AND RAMP-UP}

The interior phase was initialized as a so-called hard start, without any specific, slower ramp-up. It was soon realized that this caused various problems, the most remarkable one being the inadequate commitment of subcontractors towards takt. In addition, more time should have been reserved for inspecting the quality of the works in the first apartments, so the multiplication of defects could have been eliminated more effectively. As TPTC requires an entirely new approach to resource, task, and communication management, more preparation would have been required to engage every participant fully. Certain conflicts between the contracts and requirements for tightly controlled takt production made it also 
hard for the subcontractors to commit to the plan entirely. When the workers were paid based on piece rates, they tended to sub-optimize their own processes and leave work unfinished. Fully committing to the takt plan would have decreased their hourly payment. This problem emerged especially during drywall installation.

In addition to the need for a softer start and better engagement of subcontractors, four important enablers were identified in the early stage and ramp-up: 1) the logistic and material control plan should be addressed well before production begins, 2) takt planning should particularly focus on the specified critical tasks (such as drywalls, floor screeding and wall levelling works), 3) effective control of drying is essential for minimizing bottlenecks, and 4) the design solutions should support constructability and be finished before production begins. The latter lesson was especially realized in unsolved clashes between HVAC and architectural designs, which caused major disturbances in the early phase of production. Overall, the early-stage production suffered from several drawbacks that were not considered during the planning phase, which caused the first weeks of takt implementation to be quite chaotic. The interior phase was partially restarted between the early and mid-stages, which provided a fresh start for the next phase.

\section{MID-STAGE PRODUCTION}

After the ramp-up, several control actions were implemented to continue production with one-day takt. Tighter control provided clarification and transparency for the management as well as for the subcontractors, but at the same time, challenged all the actors to control their actions more aggressively. Tight one-day takt caused some stress for the subcontractors, and control actions caused slight fluctuations in resource alignment.

In mid-stage, the production control tended to slide towards weekly location-based control, which occurred in situations where sufficient control actions were not analyzed and planned beforehand. Although the slide to weekly control was prevented, it was realized that intensive one-day takt also required more intensive planning of control actions. More detailed planning of other functional spaces and backlog areas might have helped to achieve more proactive control. In addition, better visual guidance would have been useful to keep everyone on the site aware of the changes and control actions.

Slow concrete drying disturbed the flow in the mid-stage. This was especially noted in material-intensive tasks such as floor laminating, where disturbances in work flow caused unnecessary moving and re-storing of materials. The realized workflow of floor lamination is illustrated in Figure 3: the flow shape is significantly different than planned. Drying also affected the flow in the apartments, where the two trains clashed due of work rearrangements. Although the space for the trains was different, some work phases such as floor laminating and bathroom tiling prevented the work in the same apartment altogether. On the other hand, proactive actions and flexibility of HVAC and electricity subcontractors helped to avoid many other possible problems that could have otherwise hampered the flow. Their proactive operation demonstrated the importance of motivated subcontractors that are willing to work within tight takt controlled production.

Despite the challenges faced, the flow of the production was increased in the mid-stage. Compared to traditional location-based management, problems were quickly detected and solved, which effectively prevented possible cascading delays effectively. In addition, 
information gained from real-time tracking tools enabled a proactive and transparent way of control, and for example, the drying of concrete was addressed in real time.

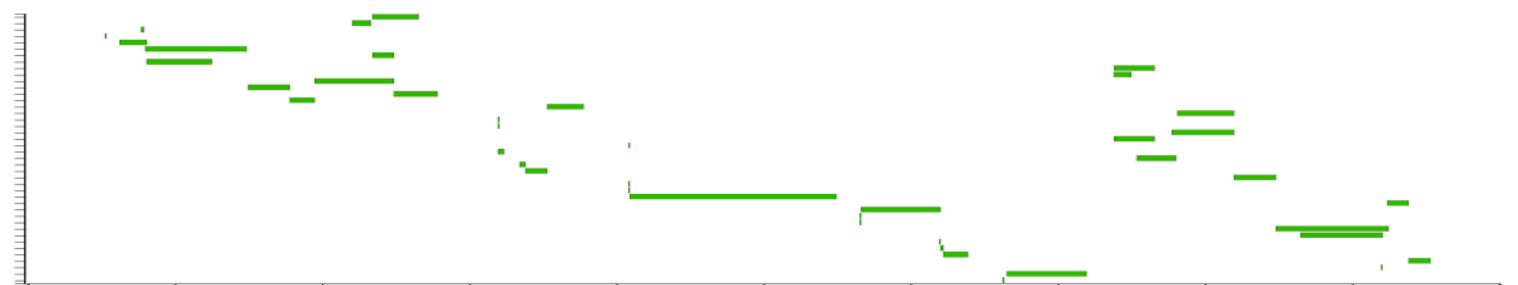

Figure 3 Illustration of realized workflow of floor lamination (from SiteDrive data)

\section{END-STAGE PRODUCTION AND HANDOVER}

Even though the middle-stage production progressed well, the production continued to slide towards the traditional weekly-based control in the end-stage. On the other hand, the actual benefits of TPTC were well-understood only at the end-stage of the interior phase. The active control of production eased the pressure during the end-stage, while most of the emerging problems were already detected and solved. In addition, the implemented digital scheduling tool allowed to look back on the realized actions, which also helped the subcontractors to gain insights and development ideas of their own performance.

The learning curve during the interior phase was steep from the viewpoint of both takt control and planning. Analysis of the lessons learned during the late production and handover allowed site management and subcontractors, but also actors involved in planning, procurement, and design operations to understand more deeply the requirements for effective TPTC. Overall, most of the actors were able to realize the potential, but also the demands of effective takt production. It is crucial to have a softer start and a detailed planning phase, where all the actors should gain an overall view of the requirements but also benefits of TPTC before the beginning of production.

\section{DISCUSSION AND RECOMMENDATIONS}

Although several items for development were observed, the implementation of takt planning and control was a success from the viewpoint of the general contractor and subcontractors. The cycle time of the internal construction phase was reduced radically by two months (nearly 30\%), with only a slight increase in directs costs and no compromise with quality. As also noticed by Vatne and Drevland (2016), TPTC made it easy to spot errors and continuously steer the production proactively. While detecting and correcting errors daily is stressful, it helps to avoid cascading delays and overall improves the flow. In addition to various lessons learned, improved transparency during production and the potential of implemented digital tools indicated that TPTC is worth implementing in the future projects as well. Project personnel estimated that a 50\% duration reduction should be possible in the future, while also improving quality and reducing costs. The analyzed and synthesized barriers are presented in Tables 2 and 3, together with the recommended enablers and actions. 
Table 2: The most significant barriers, enablers, and actions connected to takt planning

\begin{tabular}{|c|c|c|}
\hline Category & The most significant barriers & Recommended enablers and actions \\
\hline $\begin{array}{l}\text { Design } \\
\text { operations }\end{array}$ & $\begin{array}{l}\text { Unique and unfinished design } \\
\text { solutions were the root cause of } \\
\text { several bottlenecks }\end{array}$ & $\begin{array}{l}\text { Proactive and co-creative design } \\
\text { management; implementation of modular } \\
\text { solutions }\end{array}$ \\
\hline $\begin{array}{l}\text { Procurement } \\
\text { operations }\end{array}$ & $\begin{array}{l}\text { Subcontractors and material } \\
\text { suppliers were not prepared for } \\
\text { the intensive TPTC }\end{array}$ & $\begin{array}{l}\text { Ability to commit on TPTC should be } \\
\text { addressed in the procurement process; } \\
\text { more effective revenue models }\end{array}$ \\
\hline $\begin{array}{l}\text { Takt } \\
\text { planning }\end{array}$ & $\begin{array}{l}\text { Logistic and material control plan, } \\
\text { control of drying and specified } \\
\text { critical tasks were not planned } \\
\text { thoroughly before production }\end{array}$ & $\begin{array}{l}\text { Co-operation with other pre-production } \\
\text { operations; control of drying; detailed } \\
\text { planning of logistics and determined } \\
\text { critical, early-stage tasks }\end{array}$ \\
\hline $\begin{array}{l}\text { Previous } \\
\text { production } \\
\text { phases }\end{array}$ & $\begin{array}{l}\text { Lack of link of structural phase } \\
\text { schedule and interior phase takt } \\
\text { reduced the overall flow }\end{array}$ & $\begin{array}{l}\text { Takt planning should extend from } \\
\text { affecting the individual construction phase } \\
\text { towards a holistic approach }\end{array}$ \\
\hline
\end{tabular}

For more thorough preparation and planning of takt production, resources should be ensured for proactive co-operation with design operations, procurement, and trade partners. As also noted by Frandson et al. (2013), a much higher level of planning is required for effective takt. On the other hand, Binninger et al. (2018) state that even though an extended planning period increases the benefits, the planning time is always somewhat limited and therefore should also be optimized. Vatne and Drevland (2016) also suggest starting the planning earlier as well as involving craftsmen, which also resonate with the findings from this study. The focus of planning should also be more centered on detailed, daily-based logistics planning (also Vatne and Drevland, 2016), control of drying, which typically becomes the bottleneck in takt production (also Binninger et al. 2018), the determined critical early-stage tasks as well as previous or adjacent work phases. These notions agree with the findings of Frandson and Tommelein (2016) and of Binninger et al. (2018), as they suggest that the whole production systems should be balanced more holistically.

Moreover, design solutions should promote the best constructability, not only the lowest cost. In addition to proactive co-creation in the design phase, the implementation of modular solutions, especially the use of modular and prefabricated, bathrooms could streamline takt production (Chauhan et al. 2018). The implementation could lower the risks and increase the flow, while eliminating the second takt train and almost halving the number of work stages operated in a single apartment.

The subcontractor's ability to commit to takt production should be addressed already in the procurement process, as the subcontractor's ability to perform takt can be hard to determine while participating in takt-controlled production for the first time (also noted by Binninger et al. 2018). In addition, the contract model should address the revenue logic of the main contractor, the subcontractor, and the individual worker in a manner that the contract itself creates no major conflicts while performing takt production. Vatne and Drevland (2016) similarly argued that in order to gain full monetary benefits from using takt, the current pay-per-square-meter revenue logic is insufficient. 
Table 3: The most significant barriers, enablers, and actions connected to takt control

\begin{tabular}{lll}
\hline Category & The most significant barriers & Recommended enablers and actions \\
\hline Takt control & $\begin{array}{l}\text { TPTC implementation was not fully } \\
\text { addressed beforehand, while hard } \\
\text { start was too intense }\end{array}$ & $\begin{array}{l}\text { Mutual understanding of takt production } \\
\text { requirements should be ensured through } \\
\text { intensive training and a softer start }\end{array}$ \\
$\begin{array}{l}\text { Management } \\
\text { of trades and } \\
\text { tools }\end{array}$ & $\begin{array}{l}\text { Daily control was not fully } \\
\text { addressed; advantages of new } \\
\text { implemented tools not fully realized } \\
\text { due to poor data quality }\end{array}$ & $\begin{array}{l}\text { Daily control and full awareness of every } \\
\text { actor on the site is required; effective } \\
\text { learning requires better mutual } \\
\text { understanding }\end{array}$ \\
\hline
\end{tabular}

For optimal takt control, smooth onboarding with a softer start and higher-quality training is needed. The necessity of proper training of takt is also raised by Frandson et al. (2013), as they mention that the communication of the production plan and implemented methods effectively is the number one challenge of successful takt. Although construction production is by its nature always partially reactive, the methods for control and adjustment should be examined with all the actors before the production. The preparation is especially important in one-day takt, which challenges the actors to steer their actions in a somewhat hectic pace. Otherwise, production easily skids towards the traditional ways of working.

In addition to effective onboarding, daily control and constant situational awareness should be enabled. Daily routines and steering actions require a change in mindset for both management and subcontractors, but are pertinent for controlling one-day takt effectively. Moreover, the possibilities of new digital tools such as more accurate tracking of work and possibility of efficient learning should be also emphasized through the production. Digital scheduling tools could provide the needed visual guidance, a more agile and transparent daily control mechanism as well as an opportunity for continuous improvement through analysis of the collected data, but only if implemented and trained properly.

\section{CONCLUSIONS AND AVENUES FOR FUTURE RESEARCH}

The objective of the study was to address the suitability of TPTC for the interior phase of a residential construction project, where the initial goal of the implementation was to enhance flow efficiency as well as to radically shorten production duration. The study offered several lessons learned for future implementations. Even though TPTC challenged the team to work in a completely new manner and required increased effort, TPTC reduced cycle time substantially while also increasing transparency. Most of the lessons learned were related to planning operations, and several barriers should be tackled collaboratively with all the participants. If all or even some of the barriers can be solved, takt control itself could focus more on improving the production flow, and not only reactive firefighting. Further, better onboarding and adoption of digital control tools could enable more efficient takt control, but also provide an opportunity for more efficient learning from the process. It can be concluded that TPTC is suitable for improving flow efficiency and reducing duration of the interior phase of a residential construction project. The findings are based on a single case study, so further research is required to generalize the results. The future research could include addressing long-term effects takt production over several projects, and more thorough comparison of different takt methods and implementation cases. 


\section{REFERENCES}

Ballard, H. (2000). The last planner system of production control.

Binninger, M., Dlouhy, J., Müller, M., Schattmann, M., \& Haghsheno, S. (2018). Short Takt Time in Construction - a Practical Study. Proceedings (IGLC 26). Chennai, India

Binninger, M., Dlouhy, J., Steuer, D., \& Haghsheno, S. (2017). Adjustment Mechanisms for Demandoriented Optimisation in Takt Planning and Takt Control. Proceedings (IGLC 25). Heraklion, Greece

Chauhan, K., Peltokorpi, A., Seppänen, O., \& Berghede, K. (2018). Combining Takt Planning With Prefabrication for Industrialized Construction. Proceedings (IGLC 26). Chennai, India

Dlouhy, J., Binninger, M., Oprach, S., \& Haghsheno, S. (2016). Three-level method of Takt planning and Takt control-A new approach for designing production systems in construction. Proceedings (IGLC 24). Boston, USA.

Etges, B. M. B. da S., Pereira, B. B., \& Silveira, T. J. S. da. (2018). A Lean Approach to Improve Productivity in a Coke Oven Refurbishment Project: A Case Study. Proceedings (IGLC 26). Chennai, India.

Frandson, A., Berghede, K., \& Tommelein, I. D. (2013). Takt time planning for construction of exterior cladding. Proceedings (IGLC 21). Fortaleza, Brazil

Frandson, A. G., \& Tommelein, I. D. (2016). Takt time planning of interiors on a Pre-Cast hospital project. Proceedings (IGLC 24). Boston, USA.

Hopp, W., \& Spearman, M. (2008). Factory Physics. Vol. 2.

Jabrouni, H., Kamsu-Foguem, B., Geneste, L., \& Vaysse, C. (2011). Continuous improvement through knowledge-guided analysis in experience feedback. Engineering Applications of Artificial Intelligence, 24(8), 1419-1431.

Kenley, R., \& Seppänen, O. (2010). Location-based management for construction: Planning, scheduling and control. Routledge.

Koskela, L. (1992). Application of the new production philosophy to construction.

Mario, F. C., \& Howell, G. (2012). Using Production System Design and Takt Time To Improve Project Performance. Proceedings (IGLC 20). San Diego, USA

Patton, M. Q. (1999). Enhancing the quality and credibility of qualitative analysis. Health Services Research, 34(5 Pt 2), 1189-1208.

Tommelein, I. D. (2017). Collaborative Takt Time Planning of Non-Repetitive Work. Proceedings (IGLC 25). Heraklion, Greece

Vatne, M. E., \& Drevland, F. (2016). Practical Benefits of Using Takt Time Planning: A Case Study. Proceedings (IGLC 24). Boston, USA 
Lehtovaara, J., Mustonen, I., Peuronen, P., Seppänen, O., and Peltokorpi, A 